\title{
The Effect of Levamlodipine in Glucose-Induced Acute Model of Glaucoma in Rabbits
}

\author{
Waleed K. Abdulsahib*(i) \\ Department of Pharmacology and Toxicology, College of Pharmacy, Al-Farahidi University, Baghdad, Iraq
}

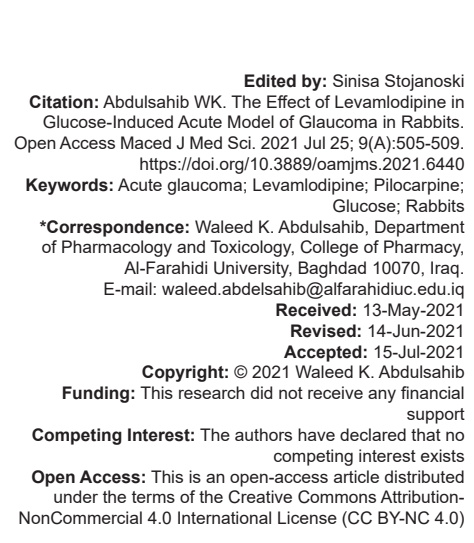

Abstract

BACKGROUND: Loss of vision and irreversible blindness are the main consequences of glaucoma. There are two main types of glaucoma: Chronic and acute.

AIM: This work aimed to evaluate the intraocular effect of levamlodipine on the acute model of glaucoma in rabbits. METHODS: Eighteen white albino rabbits of both sexes weighing about $2 \mathrm{~kg}$. We divided them into three groups (six animals in each group) used in the experiment. We use the right eye to evaluate the effect of the test drug and used the left eye as a control (vehicle only). We used the first group to evaluate levamlodipine $(0.25 \%)$, the second group to estimate levamlodipine $(0.5 \%)$, and the third group to assess pilocarpine $2 \%$ (positive control). Drugs were administered 30 min before induction.

RESULTS: Glucose (5\%) fluid produces a significant intraocular pressure (IOP) elevation after 30 min of administration in the left eye $(p<0.001)$. Pre-treatment topical administration of levamlodipine $(0.25 \%)$ prevents the rise in the IOP significantly $(p<0.001)$ in the right eye when compared to the control group (left eye). Moreover, compared with the eyes of the control group at all stages of the experiment, the topical administration of levamlodipine $(0.5 \%)$ has a significant preventable effect $(p<0.001)$, compared with the control group. The IOP of the local pilocarpine $(2 \%)$ in the third group was significantly decreased $(p<0.001)$. Finally, compared with levamlodipine $(0.5 \%)$, pilocarpine has a more significant effect in preventing a rapid increase in intraocular pressure $(p<0.001)$

CONCLUSION: Levamlodipine is a promising therapeutic agent for patients vulnerable to acute glaucoma.

\section{Introduction}

Loss of vision and irreversible blindness are the main consequences of glaucoma [1]. There are two main types of glaucoma; chronic and acute [2]. Acute glaucoma resulted from a blockage around the trabecular meshwork that allows aqueous humor $(\mathrm{AH})$ to accumulate, leading to a rise in intraocular pressure (IOP) followed by the death of retinal ganglion cells (RGCs) and retinal ischemia-reperfusion injury [3]. Today, the most common way to treat glaucoma is to lower IOP. It is supposed that the harm to RGCs and axons can be minimal by IOP reduction. If mechanical force is the only pathophysiological mechanism in glaucoma, we can prevent glaucoma progression by IOP reduction. Due to the complexity of glaucoma, about $50 \%$ of patients have normal IOP with visual field defects, so there is insufficient attention to IOP reduction strategies [4]. In addition, there are a considerable number of patients with high-tension glaucoma in whom the progression of the disease despite reduced IOP is successful [5]. An essential cell membrane protein complex that facilitates the influx of $\mathrm{Ca}++$ into the cell in response to membrane depolarization is the voltagegated L-type calcium channel CaV1.2. The increase in intracellular $\mathrm{Ca}++$ can act as a messenger to control many cellular processes, including contraction of muscle, secretion of the hormone, gene expression, and neuronal transmission. These physiological processes depend in part on the action of the CaV1.2 channel categorized as excitation-contraction, excitation-secretion, or excitation-transcription coupling [6], [7]. Amlodipine, a fundamental derivative of dihydropyridine, prevents the calcium influx to peripheral vascular and coronary smooth muscle cells through "slow" channels, causing clear vasodilation in peripheral and coronary vascular beds. Amlodipine is a racemic mixture of $(S)$ - and $(R)$-amlodipine, but only the first has therapeutic efficacy [8]. (S)Amlodipine, acknowledged as levamlodipine, is pharmacologically identical to amlodipine and has a role in vasodilation and blood pressure drop [9], [10]. In the present study, we investigated the effect of calcium channel blockers (CCBs), levamlodipine effect on IOP, and the possible mechanisms of action of this agent, the possible mechanisms of action of this agent. 


\section{Materials and Methods}

The research started on approval of the Institutional Animal Ethics Committee of the Faculty of Pharmacy, Farahidi University.

\section{Drug and chemicals}

Pure powder of levamlodipine purchased from Selleck Chemicals, and phosphate buffer purchased from Sigma-Aldrich. About 5\% glucose in water (Pioneer, Iraq), procaine hydrochloride drops (Alcaine, Belgium), and pilocarpine drops (API, Jordan) were purchased from the private market.

\section{Experimental animals}

We divided 19 white albino rabbits of both sexes (weighing about $2 \mathrm{~kg}$ ) divided into three groups (six animals in each group) used in the experiment. We use the right eye to evaluate the effect of the test drug, and we use the left eye as a control (vehicle only). We use the first group to evaluate levamlodipine $(0.25 \%)$, use the second group to evaluate levamlodipine $(0.5 \%)$, and the third group to evaluate pilocarpine $2 \%$ (positive control). Drugs were administered $30 \mathrm{~min}$ before induction. We perform an acute model of glaucoma using $5 \%$ glucose by intravenous injection at the marginal vein of the ear in dose $15 \mathrm{~mL} / \mathrm{kg}$. Before starting induction of acute glaucoma (0 times), we measure the IOP using a Schiotz tonometer and subsequently every $15 \mathrm{~min}$ until $105 \mathrm{~min}$ [2]. We carried the experimental work in the morning to avoid day and night fluctuations of intraocular pressure [11]. We used one or two drops of proparacaine to anesthetize the rabbit's eye before each reading. We were freshly prepared the levamlodipine solution by diluting the required amount in phosphate buffer [12].

\section{Statistical analysis}

We used a paired Student's t-test to analyze the data with a $95 \%$ probability level. We performed a split graph analysis of variance to study the time-dependent interaction between the drug and other drugs.

\section{Results}

Glucose (5\%) fluid produces a significant IOP elevation after 30 min of administration in the left eye $(p<0.001)$. The pre-treatment administration of topical levamlodipine $(0.25 \%)$ prevents the rise in the IOP significantly $(p<0.001)$ in the right eye when compared to the control group (left eye) at times $(30,45,60,75$, 90, and 105), as shown in Figure 1 and Table 1.

Table 1: The preventive effect of levamlodipine $(0.25 \%)$ on elevated IOP of the acute model of glaucoma in rabbits $(n=6)$

\begin{tabular}{lllllll}
\hline IOP (Initial) & \multicolumn{7}{l}{ IOP after distilled water instillation } \\
\cline { 2 - 7 } & $30 \mathrm{~min}$ & $45 \mathrm{~min}$ & $60 \mathrm{~min}$ & $75 \mathrm{~min}$ & $90 \mathrm{~min}$ & $105 \mathrm{~min}$ \\
\hline Left eye (control) & $32.98 \pm$ & $33.3 \pm$ & $32.88 \pm$ & $32.9 \pm$ & $33.5 \pm$ & $32.83 \pm$ \\
$19.13 \pm 0.43$ & 0.43 & 0.54 & 0.49 & 0.61 & 0.54 & 0.19 \\
\hline & & & & & & \\
\hline IOP after treatment & & & & & \\
\hline $\begin{array}{l}\text { Right eye } \\
\text { (levamlodipine } 0.25 \%)\end{array}$ & & & & & & \\
$\quad 19.03 \pm 0.70$ & $32.25 \pm$ & 30.55 & $27.58 \pm$ & $26.33 \pm$ & $22.88 \pm$ & $20.3 \pm$ \\
p-value & 0.93 & \pm 0.68 & 0.80 & 0.51 & 0.61 & 0.4 \\
$\quad 0.77$ & 0.12 & 0.001 & 0.001 & 0.001 & 0.001 & 0.001 \\
\hline IOP: Intraocular pressure & & & & & &
\end{tabular}

Moreover, compared with the eyes of the control group at all stages of the experiment, the topical administration of levamlodipine $(0.5 \%)$ has a significant preventable effect $(p<0.001)$, as shown in Figure 2 and Table 2. Compared with the control group, the IOP of the local pilocarpine $(2 \%)$ in the third group was significantly decreased ( $p<0.001$ ), Figure 3 and Table 3 . Finally, compared with levamlodipine $(0.5 \%)$, pilocarpine has a more significant effect in preventing a rapid increase in intraocular pressure $(p<0.001)$ as shown in Figure 4.

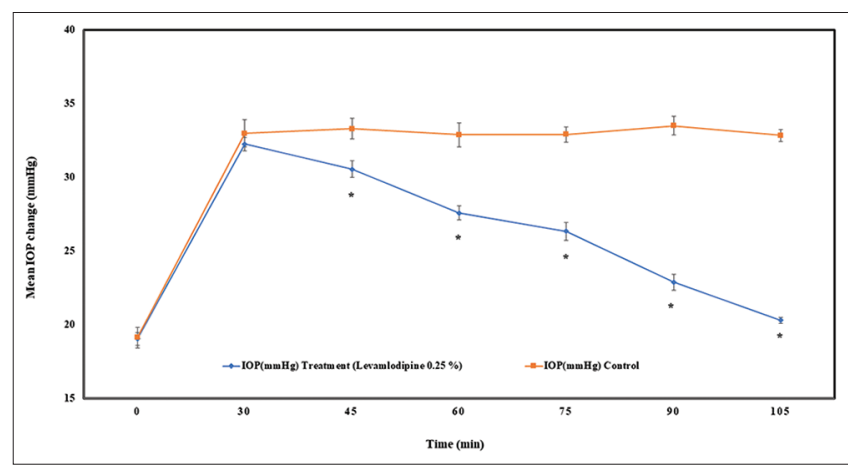

Figure 1: Impact of levamlodipine $(0.25 \%)$ on intraocular pressure of acute model of glaucoma in rabbits. Each measurement denotes the mean intraocular pressure $\pm S D M$ of six rabbits. *There is a significant difference when compared to the control $(p<0.5)$

Table 2: The preventive effect of levamlodipine $(0.5 \%)$ on elevated IOP of the acute model of glaucoma in rabbits $(n=6)$

\begin{tabular}{|c|c|c|c|c|c|c|}
\hline \multirow[t]{2}{*}{ IOP (Initial) } & \multicolumn{6}{|c|}{ IOP after distilled water instillation } \\
\hline & $30 \mathrm{~min}$ & $45 \mathrm{~min}$ & $60 \mathrm{~min}$ & $75 \min$ & $90 \mathrm{~min}$ & $105 \mathrm{~min}$ \\
\hline \multicolumn{7}{|l|}{ Left eye (control) } \\
\hline $19.01 \pm 0.52$ & $\begin{array}{l}32.83 \pm \\
0.68\end{array}$ & $\begin{array}{l}33.58 \pm \\
0.91\end{array}$ & $\begin{array}{l}32.83 \pm \\
0.51\end{array}$ & $\begin{array}{l}32.66 \pm \\
0.81\end{array}$ & $\begin{array}{l}33.16 \pm \\
0.75\end{array}$ & $\begin{array}{l}33.16 \pm \\
0.60\end{array}$ \\
\hline \multicolumn{7}{|c|}{ IOP after treatment } \\
\hline \multicolumn{7}{|c|}{ Right eye (levamlodipine $0.5 \%$ ) } \\
\hline $19.23 \pm 0.43$ & $\begin{array}{l}32.5 \pm \\
0.64\end{array}$ & $\begin{array}{l}28.46 \pm \\
0.42\end{array}$ & $\begin{array}{l}25.38 \pm \\
0.53\end{array}$ & $\begin{array}{l}21.71 \pm \\
0.64\end{array}$ & $\begin{array}{l}20.33 \pm \\
0.26\end{array}$ & $\begin{array}{l}18.63 \pm \\
0.29\end{array}$ \\
\hline \multicolumn{7}{|l|}{$p$-value } \\
\hline 0.45 & 0.40 & 0.001 & 0.001 & 0.0001 & 0.001 & 0.001 \\
\hline
\end{tabular}

\section{Discussion}

This study shows that dihydropyridinelevamlodipine can effectively prevent the progression of an acute model of glaucoma induced by glucose 


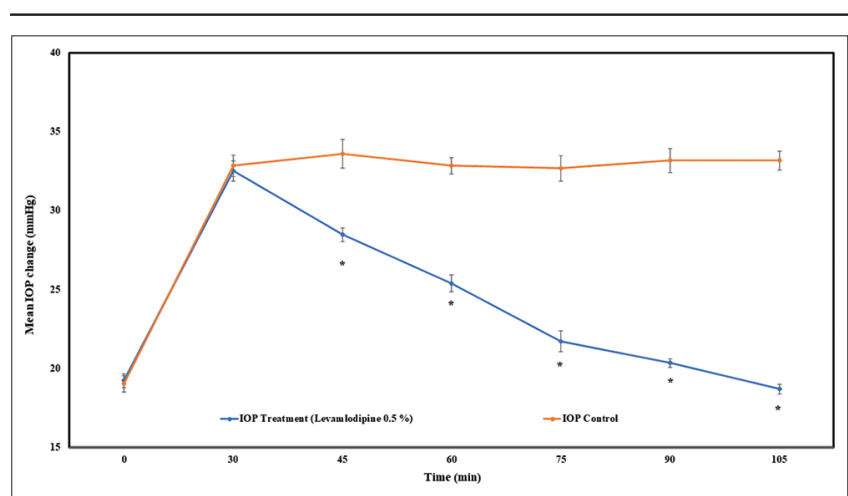

Figure 2: Impact of levamlodipine $(0.5 \%)$ on intraocular pressure of acute model of glaucoma in rabbits. Each measurement denotes the mean intraocular pressure \pm SDM of six rabbits. *There is a significant difference when compared to the control $(p<0.5)$

and suggest the paramount role of levamlodipine in the regulation of IOP. Irina et al. will strengthen this point, demonstrated the benefits of CCB in preventing the progression of adrenaline-induced acute glaucoma, especially in the early stages of the disease [13], [14].

Table 3: The preventive effect of pilocarpine $(2 \%)$ on elevated IOP of the acute model of glaucoma in rabbits $(n=6)$

\begin{tabular}{lllllll}
\hline IOP (Initial) & \multicolumn{7}{l}{ IOP after distilled water instillation } \\
\cline { 2 - 7 } & $30 \mathrm{~min}$ & $45 \mathrm{~min}$ & $60 \mathrm{~min}$ & $75 \mathrm{~min}$ & $90 \mathrm{~min}$ & $105 \mathrm{~min}$ \\
\hline Left eye (control) & $33.56 \pm$ & $33.03 \pm$ & $33 \pm$ & $32.96 \pm$ & $33.25 \pm$ & $33.16 \pm$ \\
$18.86 \pm 0.15$ & 0.47 & 0.82 & 0.89 & 0.63 & 0.68 & 0.5 \\
\hline & \multicolumn{7}{c}{} & & & & \\
\hline IOP after treatment & & & & & & \\
\hline Right eye (pilocarpine 2\%) & & & & & & \\
$\quad 18.65 \pm 0.37$ & $33.26 \pm$ & $27.33 \pm$ & $23.05 \pm$ & $19.3 \pm$ & $18.66 \pm$ & $18.35 \pm$ \\
p value & 0.44 & 1.21 & 0.64 & 0.40 & 0.21 & 0.398 \\
$\quad 0.21$ & 0.28 & 0.001 & 0.001 & 0.001 & 0.001 & 0.001 \\
\hline IOP: Intraocular pressure & & & & &
\end{tabular}

There is a close interaction between $\mathrm{Ca}++$ and adenylyl cyclase (AC) [15]. Five types of $A C$ are regulated by $\mathrm{Ca}++[16]$, stimulated three types, and two are inhibited by it [7]. The cAMP produced, especially in the ciliary body and iris by AC activation. This cAMP can affect the $\mathrm{Ca}++$ exchange, resulted in increasing $\mathrm{Ca}++$ entrance into the cell through the voltage-dependent L-type channels. This will lead to IOP elevation, so levamlodipine administration can prevent glaucoma development [17], [18]. In addition, the lowering influence of levamlodipine attributed to the reduction of $\mathrm{AH}$ by reducing cAMP accumulation [19].

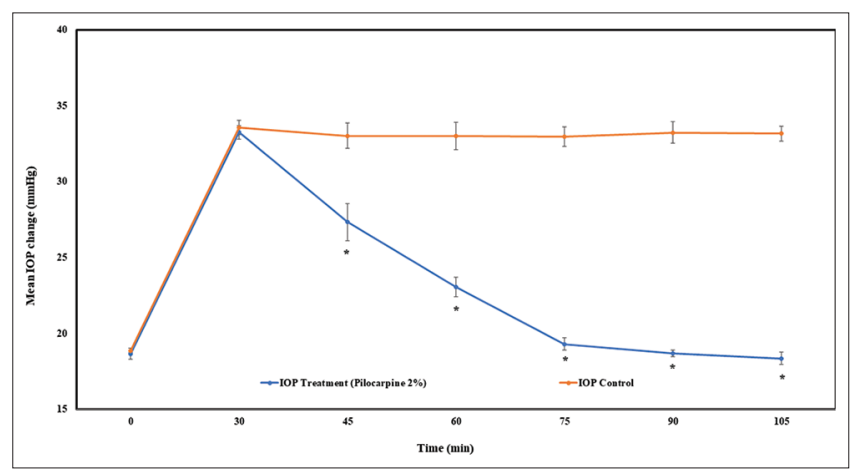

Figure 3: Impact of pilocarpine $(0.25 \%)$ on intraocular pressure of acute model of glaucoma in rabbits. Each measurement denotes the mean intraocular pressure $\pm S D M$ of six rabbits. ${ }^{*}$ There is a significant difference when compared to the control $(p<0.5)$
Similarly, the preventive effect of S-amlodipine may be due to the blocking effect of $\mathrm{Ca}++$ entry by activating cell membrane phosphorylation-dependent pathways [20]. Decreasing the influx of $\mathrm{Ca}++$ by levamlodipine can also increase outflow facilities by relaxing the muscles in trabecular meshwork cells [21]. This finding is consistent with the views of Erickson et al., and Schroeder et al. [22] showed a dose-related increase in the outflow facility after the administration of CCB in the dissected human eyes. The above findings state that topical application of forskolin (1\%) causes a decrease in CAMP which reduces IOP in humans, monkeys, and rabbits, which indicates that the net rate of $\mathrm{AH}$ inflow decreases when cAMP increases [23].

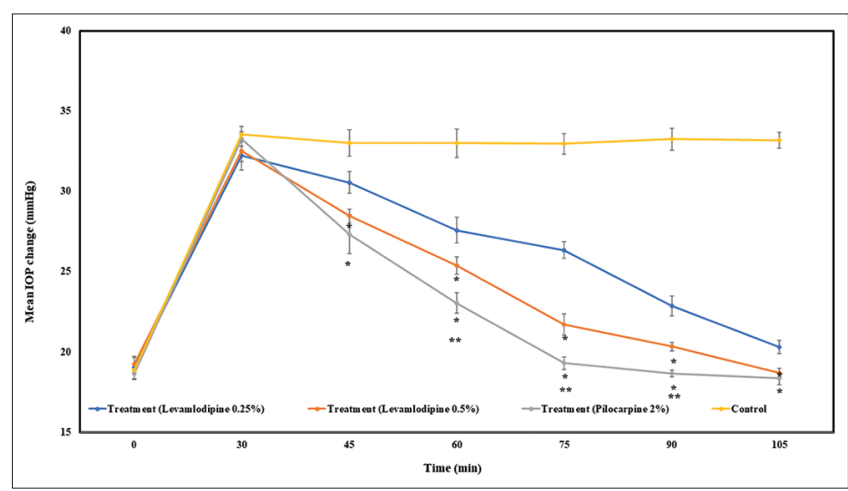

Figure 4: Impact of levamlodipine (0.25\%), levamlodipine (0.5\%), and pilocarpine $(0.25 \%)$ on intraocular pressure of acute model of glaucoma in rabbits. Each measurement denotes the mean intraocular pressure $\pm S D M$ of six rabbits. ${ }^{*}$ There is a significant difference when compared to the control $(p<0.5)$. **Significant different when compare to levamlodipine $(0.5 \%)(p<0.5)$

Decreasing episcleral venous pressure by blocking the calcium channel may directly influence the $\mathrm{AH}$ outflow. It leads to a predictable hypotensive effect of the tested drug [24]. Non-pigmented and pigmented ciliary epithelial cells contain gap junctions. Moreover, it is partially regulated by $\mathrm{Ca}++[16]$. Verapamil interferes with these connections. Verapamil causes permeability of the cell epithelium that inhibiting the formation of $\mathrm{AH}$ [25]. Changes in cAMP content in the ciliary zone also affect IOP by enhancing outflow facilities or inhibiting the formation of $\mathrm{AH}$ [14].

In addition, levamlodipine may have neuroprotective effects on RGC. Levamlodipine inhibiting glutamate release [26]. The excitatory neurotransmitter glutamate has a significant pathophysiological role in RGC death in the case of glaucoma. Levamlodipine can inhibit the release of glutamate [27] and therefore have a potential role in guard against RGCs in patients with glaucoma. This recommendation is consistent with Carol et al. [28]. In addition, the vasodilation effect of levamlodipine can prevent ischemic damage to eye tissue [29]. Extracellular matrix collagen protein synthesis also could be inhibited by CCBs, suggesting a protective role of levamlodipine in glaucoma [30]. The antihypertensive effect of levamlodipine is consistent with Waleed et al. [31] demonstrated the hypotensive effect of topical nimodipine that follows administration 
to the betamethasone model of glaucoma. Andrew et al. [32] proved that twice-daily administration of flunarizine reduces IOP in dogs after 2 days. Rabbit's experimental studies reported the hypotensive effect of a single topical administration dose of flunarizine after $1 \mathrm{~h}$ [33]. Our findings are consistent with Ashutosh et al. [34] and Irina et al. [35] reported a preventable effect of CCBs on glucose- and adrenaline-induced acute glaucoma in rabbits. In addition, the previous studies show that levamlodipine has a good impact on decreasing IOP in rabbits' chronic glaucoma models [15]. Based on these findings, we suggest that levamlodipine could deuce the $\mathrm{AH}$ production and increase outflow facility. These CCBs should be evaluated in larger animal samples to eliminate bias and withdrawal of animal blood samples to measure serum levels of the tested drug. Finally, we recommend the future evaluation of the neuroprotection effect of levamlodipine in the chronic model of glaucoma.

\section{Conclusion}

Levamlodipine is a promising therapeutic agent for patients vulnerable to acute glaucoma.

\section{Authors' Contributions}

Author Waleed K. Abdulsahib performed; conceptualization, data curation, manuscript preparation, investigation, methodology, project administration, writing - original draft, and writing review and editing. The author has read and agreed to the published version of the manuscript.

\section{References}

1. Twa MD. Intraocular pressure and glaucoma. In: Optometry and Vision Science. Vol. 95. United States: American Academy of Optometry; 2018. p. 83-5. https://doi.org/10.1097/ opx.0000000000001183

2. Abdulsahib WK, Al-Zubaidy A, Sahib HB, Kathem SH. Tolerable ocular hypotensive effect of topically applied sildenafil in ocular in normotensive and betamethasone-induced hypertensive rabbits. Int J Pharm Sci Rev Res. 2015;35(1):96-102.

3. Mead B, Tomarev S. Evaluating retinal ganglion cell loss and dysfunction. Exp Eye Res. 2016;151:96-106. https://doi. org/10.1016/j.exer.2016.08.006 PMid:27523467

4. Wolvaardt E, Stevens S. Measuring intraocular pressure Community Eye Health. 2019;32(107):56-7.

\section{PMid:32123477}

5. Cho H, Kee C. Population-based glaucoma prevalence studies in Asians. Surv Ophthalmol. 2014;59(4):434-47.

PMid:24837853

6. Striessnig J, J Ortner N, Pinggera A. Pharmacology of L-type calcium channels: novel drugs for old targets? Curr Mol Pharmacol. 2015;8(2):110-22. https://doi.org/10.2174/1874467 208666150507105845

PMid:25966690

7. Hofmann F, Flockerzi V, Kahl S, Wegener JW. L-type CaV1 2 calcium channels: from in vitro findings to in vivo function. Physiol Rev. 2014;94(1):303-26. https://doi.org/10.1152/ physrev.00016.2013 PMid:24382889

8. Bulsara KG, Cassagnol M. Amlodipine. Treasure Island, FL: StatPearls Publishing; 2020.

9. Plummer CE, Bras D, Grozdanic S, Komáromy AM, McLellan G, Miller P, et al. Prophylactic anti-glaucoma therapy in dogs with primary glaucoma: A practitioner survey of current medical protocols. Vet Ophthalmol. 2021;24(Suppl 1):96-108. https://doi. org/10.1111/vop.12820 PMid:32920915

10. Lu Y, Yin J, Wu X, Fan Y, Liu F. Comparative effects of $2.5 \mathrm{mg}$ levamlodipine and $5 \mathrm{mg}$ amlodipine on vascular endothelial function and atherosclerosis. Pak J Pharm Sci. 2019;32(5(Special)):2433-6. PMid:31894030

11. Abdulsahib WK, Abood SJ. Effect of digoxin ophthalmic solutions on the intraocular pressure in rabbits. Drug Invent Today. 2020;14(1):5-9.

12. Hussein $M Q$, Kadim HM, Abdulsahib WK. Effect of telmisartan on intra-ocular pressure in induced open angle glaucoma in rabbits. Int J Sci Res. 2015;6:2319-7064.

13. Araie M, Mayama C. Use of calcium channel blockers for glaucoma. Prog Retin Eye Res. 2011;30(1):54-71. https://doi. org/10.1016/j.preteyeres.2010.09.002

PMid:20933604

14. Abdulsahib WK. Future therapeutic strategies in the glaucoma management. J Adv Med Pharm Sci. 2020;22(7):40-9.

15. Abdulsahib WK and AJS. The effect of calcium channel blocker in the betamethasone-induced glaucoma model in rabbits. J Adv Pharm Educ Res. 2021;11(1):135-40. https://doi. org/10.51847/2d3w8vfsvt

16. Fadheel OQ, AL-Jawad FH, Abdulsahib WK, Ghazi HF. Effect Felodipine against Pilocarpine induced seizures in rats. Int Pharm Sci Rev Res. 2018;52(1):54-60.

17. Baumann L, Gerstner A, Zong X, Biel M, Wahl-Schott C. Functional characterization of the L-type $\mathrm{Ca} 2+$ channel Cav1. $4 \alpha 1$ from mouse retina. Invest Ophthalmol Vis Sci. 2004;45(2):708-13. https://doi.org/10.1167/iovs.03-0937 PMid: 14744918

18. Shim MS, Kim KY, Ju WK. Role of cyclic AMP in the eye with glaucoma. BMB Rep. 2017;50(2):60. PMid:27916026

19. Sena DF, Lindsley K. Neuroprotection for treatment of glaucoma in adults. Cochrane database Syst Rev. 2017;1(1):CD006539. PMid:28122126

20. Reves JG, Kissin I, Lell WA, Tosone S. Calcium entry blockers: Uses and implications for anesthesiologists. J Am Soc Anesthesiol. 1982;57(6):504-18. https://doi. org/10.1097/00000542-198212000-00013 PMid:6756213

21. Li X, Wang C, Li T, Liu Y, Liu S, Tao Y, et al. Bioequivalence of levamlodipine besylate tablets in healthy Chinese subjects: 
A single-dose and two-period crossover randomized study. BMC Pharmacol Toxicol. 2020;21(1):80. https://doi.org/10.1186/ s40360-020-00459-6

PMid:33213527

22. Erickson KA, Schroeder A, Netland PA. Verapamil increases outflow facility in the human eye. Exp Eye Res. 1995;61(5):5657. https://doi.org/10.1016/s0014-4835(05)80050-8 PMid:8654499

23. Majeed M, Nagabhushanam K, Natarajan $S$, Vaidyanathan $P$, Karri SK, Jose JA. Efficacy and safety of $1 \%$ forskolin eye drops in open angle glaucoma an open label study. Saudi $\mathrm{J}$ Ophthalmol. 2015;29(3):197-200. https://doi.org/10.1016/j. sjopt.2015.02.003

PMid:26155078

24. Göbel K, Rüfer F, Erb C. Physiology of aqueous humor formation, diurnal fluctuation of intraocular pressure and its significance for glaucoma. Klin Monbl Augenheilkd. 2011;228(2):104-8. PMid:21328169

25. Peracchia C. Calmodulin-mediated regulation of gap junction channels. Int J Mol Sci. 2020;21(2):485.

PMid:31940951

26. Plumbly W, Brandon N, Deeb TZ, Hall J, Harwood AJ. L-type voltage-gated calcium channel regulation of in vitro human cortical neuronal networks. Sci Rep. 2019;9(1):13810. https:// doi.org/10.1038/s41598-019-50226-9

PMid:31554851

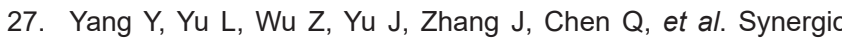
effects of levamlodipine and bisoprolol on blood pressure reduction and organ protection in spontaneously hypertensive rats. CNS Neurosci Ther. 2012;18(6):471-4. https://doi. org/10.1111/j.1755-5949.2012.00323.x PMid:22672299

28. Toris CB, Gleason ML, Camras CB, Yablonski ME. Effects of brimonidine on aqueous humor dynamics in human eyes. Arch Ophthalmol. 1995;113(12):1514-7. https://doi.org/10.1001/ archopht.1995.01100120044006

PMid:7487618

29. Yamada H, Chen Y-N, Aihara M, Araie M. Neuroprotective effect of calcium channel blocker against retinal ganglion cell damage under hypoxia. Brain Res. 2006;1071(1):75-80. https://doi. org/10.1016/j.brainres.2005.11.072

PMid:16413513

30. Quill B, Irnaten M, Docherty NG, McElnea EM, Wallace DM, Clark AF, et al. Calcium channel blockade reduces mechanical strain-induced extracellular matrix gene response in lamina cribrosa cells. Br J Ophthalmol. 2015;99(7):1009-14. https://doi. org/10.1136/bjophthalmol-2014-306093 PMid:25795916

31. Abdulsahib WK, Fadhil OQ, Tizkam HH. Effect of topically applied nimodipine on the intraocular pressure on ocular normotensive and betamethasone-induced hypertensive eyes in rabbits. Int J Res Pharm Sci. 2019;10(4):2727-32. https://doi. org/10.26452/ijrps.v10i4.1537

PMid:11163049

32. Greller AL, Hoffman AR, Liu C, Ying G, Vudathala DK, Acland GM, et al. Effects of the topically applied calcium-channel blocker flunarizine on intraocular pressure in clinically normal dogs. Am J Vet Res. 2008;69(2):273-8. https://doi.org/10.2460/ ajvr.69.2.273

PMid: 18241026

33. Maltese A, Bucolo C. Pharmacokinetic profile of topical flunarizine in rabbit eye and plasma. J Ocul Pharmacol Ther. 2003;19(2):171 9. https://doi.org/10.1089/108076803321637708 PMid:12804062

34. Ganekal S, Dorairaj S, Jhanji V, Kudlu K. Effect of topical calcium channel blockers on intraocular pressure in steroid-induced glaucoma. J Curr glaucoma Pract. 2014;8(1):15-9. https://doi. org/10.5005/jp-journals-10008-1155

\section{PMid:26997802}

35. Mikheytseva IN, Kashintseva LT, Krizhanovsky GN, Kopp OP, Lipovetskaya EM. The influence of the calcium channel blocker verapamil on experimental glaucoma. Int Ophthalmol. 2004;25(2):75-9. https://doi. org/10.1023/b: inte.0000031737.08988.b0

PMid:15290885 